\title{
BUDAYA ORGANISASIONAL, KEPUASAN KERJA, DAN KOMITMEN ORGANISASIONAL DALAM MENINGKATKAN PERILAKU INOVATIF
}

\author{
Nur Wahyunianti Dahri ${ }^{1}$, Muhammad Aqiil ${ }^{2}$ \\ ${ }^{1}$ STIE Muhammadiyah Mamuju \\ muh_aqil@stiemmamuju.ac.id \\ ${ }^{2}$ STIE Muhammadiyah Mamuju \\ nurwd@stiemmamuju.ac.id
}

\begin{abstract}
Human resources is a very important factor as a driver in the face of global current era. The competitiveness of an organization depends on human resources owned. Particularly associated with either organizational commitment and innovative behavior. This research would like to see more activities and responsibilities in developing organizational commitment, organization culture, and job satisfaction to improving employee's innovative behavior.
\end{abstract}

Keywords: Organizational culture, job satisfaction, organizational commitment and innovative behavior.

() 2018 JBTI. All rights reserved

Article history : received 23 Sep 2018; revised 5 Okt 2018; accepted 25 Okt 2018

\section{PENDAHULUAN}

Komitmen organisasional digambarkan sebagai sikap yang dimiliki oleh karyawan terhadap kebijakan dan kegiatan organisasi - tempat individu bekerja (Long, 1998). Komitmen organisasional yang tinggi menunjukkan outcome sikap positif pada organisasi (Palupi \& Tjahjono, 2016). Penelitian terdahulu membuktikan adanya hubungan erat antara komitmen organisasional dengan kepuasan kerja (Mowday et al, 1982; Saks et al, 1996; Bhuian et al, 1994; Elangovan, 2001; Tjahjono et al., 2015).

Sebagai faktor determinan yang menentukan komitmen organisasional dalam penelitian ini ada sejumlah prediktor yang dikembangkan oleh Simmons (2005) diantaranya adalah budaya organisasional dan kepuasan kerja. Meskipun demikian ada pula yang berpendapat bahwa sebetulnya kepuasan kerja merupakan sikap (attitude) yang sejajar posisinya dengan komitmen organisasi (Barney dan Griffin, 1992). Oleh karena itu dalam berbagai penelitian tentang hubungannnya dengan komitmen organisasional, kepuasan kerja dapat diposisikan sebagai variabel bebas (Witt, 1993) atau sebagai variabel terikat (Wu dan Norman, 2006) dan bahkan dikaji secara resiprokal dimana kedua variabel saling berhubungan secara timbal balik,tergantung kerangka penelitian yang digunakan masing-masing peneliti.

Dampak perilaku yang ditimbulkan oleh komitmen organisasional dalam penelitian ini difokuskan pada konsekuensi perilaku inovatif (innovative behavior) positif individu tertentu yang secara empiris dikembangkan oleh De Jong dan Kemp (2003). Unsur- unsur perilaku inovatif yang dibentuk komitmen organisasional ini sejalan dengan harapan bagi suatu perusahaan, yang membutuhkan perilaku positif dari individu sebagai karyawan. 
Tulisan ini ingin melihat lebih jauh pentingnya budaya organisasional dan kepuasan kerja dalam meningkatkan komitmen organisasional dalam meningkatkan perilaku inovatif karyawan dengan perspektif interaksi simbolik yang berusaha memahami perilaku manusia dari sudut pandang subjek. Perspektif ini menyarankan bahwa perilaku manusia harus dilihat sebagai proses yang memungkinkan manusia membentuk dan mengatur perilaku mereka dengan mempertimbangkan ekspektasi orang lain yang menjadi mitra mereka. Definisi yang mereka berikan kepada orang lain, situasi, objek, dan bahkan diri mereka sendirilah menentukan perilaku mereka (Muhadjir, 1996).

\section{KAJIAN TEORI}

\section{A. Budaya Organisasi}

Budaya berasal dari kata culture ini diadaptasi dari bahasa Latin, yaitu cult yang berarti mendiami, mengerjakan, atau memuja, dan are yang berarti hasil dari sesuatu. Warner dan Joynt (2002) mengartikan budaya dari Berthon (1993) sebagai hasil dari tindakan manusia. Budaya dalam suatu organisasi merupakan karakteristik semangat atau suasana (spirit) dan kepercayaan (belief) yang dilakukan di dalam organisasi tersebut (Torrington, 1994). Budaya yang ada pada suatu organisasi akan berbeda dengan organisasi lainnya sebagai suatu identitas unik (Tjahjono, 2004). Lebih lagi organisasi yang ada pada negara yang berbeda. Oleh karena itu, kita perlu memahami perbedaan budaya antarnegara yang sangat beragam sehingga dapat mengelola perbedaan tersebut.

Menurut Kast dan Rosenzweig (1985) memberikan definisi budaya organisasional sebagai sistem nilai dan kepercayaan yang dianut bersama yang berinteraksi dengan orangorang suatu perusahaan, strukur organisasi dan sistem pengawasan untuk menghasilkan norma-norma perilaku. Sedangkan Schein (1996) mendefinisikan budaya sebagai pola dari asumsi dasar yang telah ditentukan atau dikembangkan untuk mempelajari cara-cara berintegrasi, yang telah berfungsi dengan baik yang telah dianggap baru oleh karenanya harus diajarkan kepada anggota baru sebagai cara yang besar untuk memikirkan, memandang dan merasa berkepentingan dengan masalah tersebut. Berbagai definisi tentang budaya perusahaan tersebut menyimpulkan betapa budaya perusahaan sangat mempengaruhi berbagai aspek kehidupan bisnis.

Budaya organisasional atau perusahaan bersifat sangat persuasif dan mempengaruhi hampir keseluruhan aspek kehidupan organisasi. Demikian juga budaya organisasi mampu menumpulkan atau membelokkan dampak perubahan organisasi yang sudah direncanakan secara matang. Pada dasarnya, budaya organisasi atau perusahaan menjelma dalam berbagai wujudnya dan karena bisa mendukung atau menghambat perubahan.

Munculnya budaya organisasional dipengaruhi oleh berbagai macam faktor yang berkaitan dengan eksistensi organisasi. Nankervis et al. (1993) mengidentifikasikan sejumlah faktor yang mempengaruhi budaya organisasional diantaranya adalah "company history, present management style, size, structure, the nature of product or services, industrial relations activities, dan national culture". Berdasarkan identifikasi ini, budaya organisasional yang berkembang dalam suatu organisasi tidak dapat terlepas dari dinamika situasi unsur-unsur internal dan eksternal organisasi.

\section{B. Kepuasan Kerja}

Kepuasan kerja merupakan seperangkat perasaan individu tentang persepsi yang menyenangkan atau tidak menyenangkan dari lingkungan organisasi dan pekerjaan yang dilakukan (Barney dan Griffin, 1992). Davis dan Newstroom (1993) mendefinisikan 
kepuasan kerja sebagai kesesuaian antara harapan seseorang yang timbul dan imbalan yang diterima dari pekerjaan. Kepuasan kerja merupakan generalisasi persepsi individu terhadap pekerjaannya berdasarkan atas aneka ragam tugas dan pekerjaan yang dipengaruhi oleh sejumlah faktor.

Luthans (1985) menyatakan bahwa terdapat beberapa faktor yang mempengaruhi kepuasan kerja, yaitu: 1). Pekerjaan itu sendiri, isi dari pekerjaan itu sendiri adalah sumber utama dari kepuasan kerja, sebagaimana dikemukakan oleh Luthans (1985) yang menyatakan bahwa "some of the most important ingredients of a satisfying job uncovered by surveys include interesting and challenging work, work tha is not boring, and a job that provides status". Dengan demikian pekerjaan yang dapat mempengaruhi kepuasan adalah suatu pekerjaan yang mampu mempresentasikan peran penting bagi individu. 2). Pembayaran (upah atau gaji), individu melihat pembayaran sebagai cerminan organisasi dalam menghadapi kontribusinya dalam mencapai tujuan yang telah ditetapkan. Upah atau gaji merupakan faktor yang signifikan dalam meningkatkan kepuasan kerja (Long, 1998). 3). Promosi, kesempatan untuk mendapat promosi bagi individu mempengaruhi tingkat kepuasan tertentu. Dalam promosi pekerjaan atau jabatan, di dalamnya terkandung pula sejumlah bentuk lain, misalnya kenaikan gaji atau upah yang menyertai promosi setiap individu. 4). Teman sekerja (co-workers), kesetiakawanan, kerukunan dan kesediaan untuk saling bekerjasama antara teman sekerja merupakan sumber bagi peningkatan kepuasan kerja. Kelompok kerja yang kohesif mampu menciptakan suasana lingkungan kerja menjadi lebih menyenangkan. 5). Kondisi kerja, faktor ini lebih banyak berkaitan dengan kondisi fisik lingkungan kerja. Jika kondisi kerjanya berkualitas baik, misalnya tampak bersih dan menarik, maka individu akan dapat lebih semangat melaksanakan pekerjaannya. Sebailiknya jika kondisi lingkungan kerja tidak berkualitas baik misalnya kotor, berisik, dan panas maka individu seringkali tidak betah dan mengeluh dalam bekerja. 6). Pengawasan atau penyeliaan (supervisory), Cara organisasi mengawasi individu selama bekerja juga merupakan faktor yang mempengaruhi kepuasan kerja. Individu yang mendapat pengawasan dengan cara yang lebih manusiawi dan bersahabat akan lebih senang dibandingkan jika organisasi mengawasinya dengan cara yang sifatnya tidak bersahabat.

\section{Komitmen organisasional}

Komitmen organisasional merupakan usaha untuk mengidentifikasi diri dan melibatkan diri dalam organisasi dan berharap tetap menjadi anggota organisasi (Robbins, 2001). Mowday (1982) mendefinisikan komitmen sebagai kekuatan relatif dari identifikasi individu dan keterlibatannya dengan organisasi kerja. Meyer dan Herscovith (2001) mendefinisikan komitmen sebagai suatu kekuatan atau setting pemikiran yang mengikat individu kedalam suatu tindakan untuk terikat kepada suatu tujuan atau lebih.

Menurut Allen dan Meyer (1990), komitmen organisasional merupakan kelekatan emosi, identifikasi dan keterlibatan individu dengan organisasi serta keinginan untuk tetap menjadi anggota organisasi. Menurut Allen dan Meyer (1990), ada tiga komponen dalam komitmen organisasional, yaitu: 1). affective, yaitu komitmen yang menunjukkan keinginan karyawan untuk melibatkan diri dan mengidentifikasi diri dengan organisasi karena adanya kesesuaian nilai-nilai dalam organisasi. 2). continuance, yaitu komitmen yang timbul karena ada kekhawatiran terhadap kehilangan manfaat yang biasa diperoleh dari organisasi. 3). normative, yaitu komitmen yang muncul karena karyawan merasa berkewajiban untuk tinggal dalam organisasi. 


\section{Perilaku Inovatif}

Perilaku inovatif menurut Price (1997) pada dasarnya merupakan kemampuan individu melakukan perubahan cara kerja dalam bentuk mengadopsi prosedur, praktek dan teknik kerja yang baru dalam menyelesaikan tugas dan pekerjaanya. Gaynor (2002), mendefinisikan perilaku inovatif sebagai tindakan individu untuk menciptakan dan mengadopsi ide-ide/ pemikiran atau cara-cara baru guna diterapkan dalam pelaksanaan dan penyelesain pekerjaan.

Perilaku inovatif bukanlah semata-mata dipengaruhi faktor bawaan atau internal. Perilaku inovatif dalam bekerja sering muncul manakala seorang karyawan menghadapi tantangan dalam pekerjaannya, mendapat kewenangan yang luas dalam melaksanakan tugas dan tanggungjawabnya. Menurut De Jong dan Kemp (2003) inovasi dapat diartikan sebagai semua tindakan individu yang diarahkan pada kepentingan organisasi dimana didalamnya dilakukan introduksi dan aplikasi ide-ide baru yang menguntungkan.

Ada 3 (tiga) fase dalam melakukan proses inovasi, adalah sebagai berikut: 1. Generating ideas, keterlibatan individu dan tim dalam menghasilkan ide untuk memperbaiki produk, proses dan layanan yang ada dan menciptakan sesuatu yang baru. 2 . Harvesting ideas, melibatkan sekumpulan orang untuk mengumpulkan ide-ide yang telah ada dan melakukan evaluasi terhadap ide-ide tersebut. 3. Developing and implementing idea, mengembangkan ide-ide yang telah terkumpul dan selanjutnya mengimplementasikan ide-ide tersebut.

\section{PEMBAHASAN}

Budaya organisasional dan kepuasan kerja adalah variabel yang sangat penting bagi setiap organisasi untuk membangun sikap komitmen organisasional dan perilaku yang inovatif dalam konteks pencapaian kinerja organisasi Perilaku kerja yang positif dalam bentuk inovasi (innovative behavior) menjadi bagian yang penting untuk mempersiapkan kemampuan daya saing. Dengan demikian pengembangan budaya organisasional dan kepuasan kerja dapat menciptakan iklim organisasi yang positif (Wallace et al., 1999) sebagai kebutuhan mutlak untuk dapat mendorong terciptanya perilaku inovatif.

Penelitian yang dilakukan oleh Rashid et al. (2003) telah membuktikan adanya pengaruh budaya organisasi terhadap kinerja di beberapa perusahaan di Malaysia. Dengan menggunakan tipologi budaya organisasional dari Desphande dan Farley (2004) dan penelitian Rashid et al. (2003) menunjukkan bahwa terdapat pengaruh yang signifikan budaya organisasional terhadap peningkatan kinerja.

Implikasi temuan hasil penelitian memberikan pengertian yang lebih baik tentang hubungan faktor-faktor yang terdapat dalam budaya organisasional dalam rangka meningkatkan efektifitas manajerial dan keberhasilan organisasi. Hasil penelitian Wallace et al. (1999) menunjukkan bahwa budaya organisasional mampu membentuk iklim yang kondusif bagi nilainilai manajerial organisasi dan penelitian Erickson (1996) menekankan aspek lingkungan organisasi yang berorientasi pada budaya riset dan pengembangan sebagai faktor penting perusahaan untuk menghadapi persaingan.

Perilaku inovatif merupakan konsekuensi dari sejumlah persepsi dan sikap individu (Hult et al, 2004). Kepuasan kerja merupakan salah satu bentuk proses persepsi individu terhadap lingkungannya. Niu (2014) dalam penelitiannya pada industri jasa di Taiwan yang menyatakan bahwa perilaku inovatif dapat dipengaruhi oleh kepuasan kerja, karena perilaku inovatif bukanlah hal bawaan dari karyawan melainkan sebuah perilaku yang dapat dirangsang dengan meninhgkatkan kepuasan kerja karwayan. Tulisan ini mengembangkan konsekuensi komitmen 
organisasional dalam bentuk perilaku inovatif dengan merujuk pada kajian yang dilakukan oleh Vermeulen (2004) menekankan pentingnya mengelola perilaku inovatif sebagai upaya dalam meningkatkan kepuasan kerja untuk membangun komitmen organisasi karyawan. De Jong dan Kemp (2003).

\section{A. Budaya organisasional dan komitmen organisasional.}

Budaya organisasional memiliki pengaruh terhadap komitmen organisasional. Hal ini mendukung penelitian yang dilakukan Kim dan Rowley (2005), Rashid et al. (2003) dan Sadri dan Less (2001). Penelitian Kim and Rowley (2005) menunjukkan bahwa budaya organisasional memiliki pengaruh terhadap komitmen organisasional. Penelitian Rashid et al. (2003) menunjukkan bahwa budaya organisasi dan komitmen mempengaruhi kinerja organisasi. Penelitian Sadri and Lees (2001) menunjukkan bahwa budaya organisasional harus diintegerasikan dengan nilai-nilai individual untuk membangun organisasi yang kuat yang pada gilirannya akan menumbuhkan kemampuan organisasi dalam bersaing (competitive adventage).

\section{B. Kepuasan Kerja dan Komitmen organisasional}

Kepuasan kerja mempunyai pengaruh terhadap komitmen. Hal ini menguatkan hasil penelitian yang dilakukan oleh Wu dan Norman (2006), Yousef (1998) dan Martin and O'Laughlin (1984). Penelitian Wu dan Norman (2006) menunjukkan adanya korelasi positif antara kepuasan kerja dengan komitmen organisasional. Penelitian Yousef (1998) menunjukkan bahwa secara positif, kepuasan kerja merupakan prediktor bagi komitmen organisasional. Sementara penelitian Martin and O'Laughlin (1984) menunjukkan bahwa peningkatan kepuasan kerja di kalangan karyawan paruh waktu pada sebuah Batalion Angkatan Darat Amerika Serikat secara konsisten mempengaruhi peningkatan komitmen organisasional.

\section{Budaya organisasional dan Perilaku Inovatif}

Budaya organisasional mempunyai pengaruh terhadap perilaku inovatif, Hal ini menguatkan hasil penelitian yang dilakukan oleh Desphande dan Farley (2004), Hult et al. (2004), Wallace et al. (1999) dan Erickson (1996). Keterkaitan antara budaya organisasional dan perilaku inovatif merupakan pusat perhatian dari penelitian Desphande and Farley (2004). Hult et al. (2004) dalam penelitiannya menyatakan bahwa dalam lingkungan perusahaan yang penuh dengan tantangan, budaya organisasional merupakan determinan utama bagi perilaku inovatif untuk mencapai kinerja perusahaan secara optimal. Hasil penelitian Wallace et al. (1999) menunjukkan bahwa budaya organisasional mampu membentuk iklim yang kondusif bagi nilai-nilai manajerial organisasi.

\section{Kepuasan Kerja dan Perilaku Inovatif}

Kepuasan kerja mempunyai pengaruh terhadap perilaku inovatif. Hal ini menguatkan hasil penelitian yang dilakukan oleh Ayala, Silla, Tordera, Lorente, dan Yeves (2017) yang dilakukan pada karyawan di Spanyol yang menunjukkan bahwa karwayan yang puas akan cenderung meningkatkan perilaku inovatif dalam bekerja. Niu (2014) dalam penelitiannya terhadap industri jasa di Taiwan yang menyatakan bahwa perilaku inovatif dapat dipengaruhi oleh kepuasan kerja, karena perilaku inovatif bukanlah hal bawaan dari karyawan melainkan sebuah perilaku yang dapat dirangsang dengan meningkatkan 
kepuasan kerja karyawan. Begitupun dengan penelitian yang dilakukan Attiq, Wahid, Javaid, Kanwal, dan Shah (2017) yang dilakukan pada karyawan di Islamabad dan Rawalpindi yang menjelaskan bahwa kepuasan kerja berpengaruh terhadap perilaku inovatif. Pembentukan kepuasan kerja karyawan perlu dilakukan untuk meningkatkan perilaku inovatif untuk melakukan sebuah perubahan.

\section{E. Komitmen organisasional dan Perilaku Inovatif}

Komitmen organisasional mempunyai pengaruh terhadap perilaku inovatif. Hal ini menguatkan hasil penelitian yang dilakukan oleh Vermeulen (2004) menekankan pentingnya mengelola inovasi produk melalui upaya dalam membangun komitmen organisasional. Hasil penelitiannya juga mengidentifikasikan proses inovasi dapat diatasi dengan peningkatan komitmen organisasional seiring dengan berbagai hambatan internal. De Jong dan Kemp (2003) dalam penelitiannya menunjukkan bahwa persepsi terhadap tantangan pekerjaan, otonomi, perhatian pada strategi, kontak eksternal dan diferensiasi pasar secara positif mempengaruhi terciptanya perilaku inovatif .

\section{KESIMPULAN}

Berdasarkan pembahasan dalam penelitian ini diperoleh simpulan atas masalah penelitian bahwa budaya organisasional dan kepuasan kerja berpengaruh terhadap komitmen organisasional serta budaya organisasional, kepuasan kerja dan komitmen organisasional berpengaruh terhadap kinerja karyawan. Hal ini menunjukkan bahwa upaya meningkatkan perilaku inovatif karyawan dapat dilakukan melalui peningkatan budaya organisasional, kepuasan kerja dan komitmen organisasional.

Dampak perilaku yang ditimbulkan oleh komitmen organisasional dalam penelitian ini difokuskan pada konsekuensi perilaku inovatif (innovative behavior) positif individu tertentu yang secara empiris dikembangkan oleh De Jong dan Kemp (2003). Unsur- unsur perilaku inovatif yang dibentuk komitmen organisasional ini sejalan dengan harapan bagi suatu perusahaan, yang membutuhkan perilaku positif dari individu sebagai karyawan.

Budaya organisasional dan kepuasan kerja dianggap sangat penting dalam meningkatkan komitmen organisasi dan perilaku inovatif, oleh karena itu organisasi harus mampu untuk memperbaiki implementasi variabel-variabel tersebut, melalui upaya peningkatan praktek manajemen sumber daya manusia di dalam organisasi yang mendasarkan pada nilai-nilai obyektifitas.

\section{DAFTAR PUSTAKA}

Allen, N.J., and J.P. Meyer, (1990), The Measurement and Antecedent of Affective, Continuance, and Normative Commitment to The Organization. Journal of Occupational Psycology. 63 (1): $1-18$.

Attiq, S., Wahid, S., Javaid, N., Kanwal, M., \& Shah, H. J., (2017). The Impact of Employees' Core Self-Evaluation Personality Trait, Management Support, Co-worker Support on Job Satisfaction, and Innovative Work Behaviour. Pakistan Journal of Psychological Research, 32(1).

Ayala, Y., Silla, J. M. P., Tordera, N., Lorente, L., \& Yeves, J., (2017). Job Satisfaction and Innovative Performance in Young Spanish Employees: Testing New Patterns in the Happy- 
Productive Worker Thesis-A Discriminant Study. Journal of Happiness Studies, 18(5), 1377-1401.

Barney, J.B. and Griffin, R.W., (1992), Management of Organizations: Strategy, Structure, \& Behavior, Boston, Houghton Mifflin Company.

Berthon, P.R., (1993). Psychological type and corporate culture: Relationship and dynamics. Omega, 21(3), 329-344.

Bhuian, S.N., E.S.Al-Shammari, O.A. Jefri, and J.N. Prasad, (1994), Organizational commitment, job satisfaction and job characteristics: an empirical study of expatriates in Saudi Arabia. International Journal of Commerce and Management. 6 (3/4): 57-69

Davis, K., and J.W. Newstrom, (1993), Human Behavior at Work. New York, McGraw-HillBook Company.

De Jong, J.PJ., and R.Kemp, (2003), Determinants of Co-Workers' Innovative Behavior. An Investigation Into Knowledge Intensive Service. International Journal of Innovation Management. 7 (2): 189-212.

Deshpande, R., and J.U. Farley, (2004), Organizational culture, market orientation, innovativeness, and firm performance: an international research odyssey. International Journal of Research in Marketing. 21 (1): 3-22.

Elangovan, A.R., (2001), Causal Ordering of Stress, Satisfaction and Commitment and Intention to Quit: a Structural Equations Analysis. Leadership and Organization Development Journal. 22 (4): 159-165.

Erickson, G.S., (1996), Environment and innovation; the case of the small entity. Industrial Marketing Management. 25 (6): 577-587.

French, W.L., Kast, F.E., \& Rosenzweig, J.E. (1985). Understanding human behavior in organizations. Harper \& Row.

Gaynor, G.H., (2002), Innovation by design. New York, American Management Association.

Hult, G.T.M. R.F. Hurley, and G.A. Knight, (2004), Innovativeness: its Antecedents and Impact on Business Performance. Industrial Marketing Management. 33 (5): 429-438.

Joynt, P., \& Warner, M. (Eds.). (2002). Managing across cultures: Issues and perspectives. Cengage Learning EMEA.

Kim, J.W., and C. Rowley, (2005), Employee Commitment: a Review of The Background, Determinant and Theoretical Perspectives. Asia Pacific Bussiness Review. 11 (1): 105-124.

Long, R.J., (1998), Compensation in Canada: Strategy, Practice, and Mitchell, H., \& S. Lee, (2001), Why People Stay: Using Job Embeddedness to Predict Voluntary Turnover. The Academy of Management Journal. 44 (6): 1102-1121.

Luthans, F., (1985), Organizational Behavior (4th ed.). New York, McGraw-Hill Book Company.

Martin, Y.N., and M.S. O'Laughlin, (1984). Predictors of Organizational Commitment: The Study of Part-Time Army Reservists. Journal of Vocational Behavior. 25 (3): 270-283.

Meyer, J.P., and L. Herscovitch, (2001), Commitment in The Workplace: Toward a General Model. Human Resource Management Review. 11 (2): 299-326.

Mowday, R.T., L.W. Porter, and R.M. Steers, (1982), Employee-Organization Linkages. New York, Academic Press. 
Muhadjir, N., (1996). Metodologi penelitian kualitatif: pendekatan positivistik, rasionalistik, phenomenologik, dan realisme metaphisik telaah studi teks dan penelitian agama. Rake Sarasin.

Nankervis, AR., R.L., Compton, and T.E. McCarthy, (1993), Strategic Human Resource Management. South Melbourne, ITP Thomas Nelson Australia.

Niu, H. J. (2014). Is innovation behavior congenital? Enhancing job satisfaction as a moderator. Personnel Review, 43(2), 288-302.

Palupi, M. \& Tjahjono, H.K., (2016). A model of religiousity and organizational justice: The impact on commitment and dysfunctional behavior. Proceedings of the 27th International Business Information Management Association Conference - Innovation Management and Education Excellence Vision 2020: From Regional Development Sustainability to Global Economic Growth.

Price, J.L., (1997), Handbook of Organizational Measurement. International Journal of Manpower. 18 (4/5/6): 305-558.

Rashid, M.Z.A., M. Sambasivan, and J. Johari, (2003), The Influence of Corporate Culture and Organizational Commitment on Performance. Journal of Management Development. 22 (8): 708-728.

Robbins, S.P., (2001), Organizational Behavior. Concept, Controversies, Applications, Englewood Cliffs, NJ : Prentice Hall.

Sadri, G., and B. Lees, (2001), Developing Corporate Culture as Competitive Advantage. Journal of Management Development. 20 (10) 853-859

Saks, A.M., P.E. Mudrack, and B.E.Ashforth, (1996), The relationship between the Work ethic, job attitude, intentions to quit, and turnover for temporary service employees. Canadian Journal of Administrative Science. 13 (3): 226-241.

Schein, E.H., (1996). Three cultures of management: The key to organizational learning. Sloan management review, 38(1), 9-20.

Sikorska-Simmons, E., (2005). Predictors of organizational commitment among staff in assisted living. The Gerontologist, 45(2), 196-205.

Tjahjono, H.K., (2004). Budaya organisasional dan balanced scorecard. UPFE UMY

Tjahjono, H.K., Palupi, M. \& Dirgahayu, P., (2015), Career perception at the republic indonesia police organization impact of distributive fairness and career satisfaction on affective commitment. International Journal of Administrative Science and Organization, 22 (2): $130-135$

Torrington, D., (1994). International human resource management: Think globally, act locally. Prentice Hall.

Vermeulen, P., (2004), Managing product innovation in financial services firms European Management Journal. 22 (1) : 43-50.

Wallace, J.J., Hunt, \& C. Richards, (1999), The Relationship Between Organizational Culture, Organizational Climate and Managerial Values. The International Journal of Public Sector Management. 12 (7): 548-567.

Witt, L.A., (1993). Reactions to work assignment as predictors of organizational commitment: The moderating effect of occupational identification. Journal of Business Research, 26(1), 1730 . 
Wu, L., \& Norman, I. J. (2006). An investigation of job satisfaction, organizational commitment and role conflict and ambiguity in a sample of Chinese undergraduate nursing students. Nurse education today, 26(4), 304-314.

Yousef, D.A., (1998). Satisfaction with job security as a predictor of organizational commitment and job performance in a multicultural environment. International Journal of Manpower, 19(3), 184-194. 